DE

M E D I C I N A

T R O P I C A L

$\mathrm{DE}$

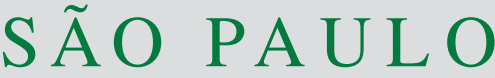

JOURNAL OF THE SÃO PAULO INSTITUTE OF TROPICAL MEDICINE

${ }^{1}$ Universidade do Estado do Rio de Janeiro, Faculdade de Ciências Médicas, Rio de Janeiro, Rio de Janeiro, Brazil

${ }^{2}$ Centro Universitário Serra dos Órgãos, Teresópolis, Brazil

${ }^{3}$ Universidade do Grande Rio, Duque de Caixas, Rio de Janeiro, Brazil

Correspondence to: Denise Leite Maia Monteiro

Universidade do Estado do Rio de Janeiro, Faculdade de Ciências Médicas, Avenida Professor Manoel de Abreu, 500, Vila Isabel, CEP 20550-170, Rio de Janeiro, RJ, Brazil

Tel: + 55021999718114

E-mail: denimonteiro2@yahoo.com.br

Received: 19 April 2018

Accepted: 24 July 2018

\section{Knowledge on the HPV vaccine among university students}

\author{
Denise Leite Maia Monteiro,2, Leila Cristina Soares Brollo1, Tayná Pinheiro \\ de Souza1, Joanna Rangel Peixoto dos Santos', Gildásio Rocha Santos ${ }^{1}$, \\ Tatiane Correa ${ }^{1}$, Julie Teixeira da Costa ${ }^{1}$, Marco Aurélio Pinho de Oliveira', \\ Alexandre José Baptista Trajano ${ }^{1,3}$
}

\section{ABSTRACT}

The objective is to evaluate knowledge on HPV vaccine and its use among university students. This is a cross-sectional study with 301 participants, of which 202 medical students from UERJ and UNIFESO (101 freshmen $=$ M1 and 101 from the $6^{\text {th }}$ year $=$ M2 $)$ and 99 UERJ literature students ( 50 freshmen $=\mathrm{L} 1$ and 49 of the last year $=\mathrm{L} 2)$. Information was obtained by questionnaires. Input and statistical analysis were carried out with the EPI-INFO 3.5.2 Program. Results showed that, among medical students, $21 \%$ of M1 and 16\% of M2 used the HPV vaccine ( $\mathrm{p}=0.35)$, mostly adopted by women $(\mathrm{M} 1=29.7 \%$ and $\mathrm{M} 2=21.3 \%$ ) than men $(\mathrm{M} 1=5.4 \%$ and $\mathrm{M} 2=7.5 \%)$. Similarly, female students showed more interest in using the vaccine $(\mathrm{M} 1=85.1 \%$ and $\mathrm{M} 2=80 \%)$ than male $(\mathrm{M} 1=56.2 \%$ and $\mathrm{M} 2=20.5 \%)$. Among literature students, only women received the vaccine $(\mathrm{L} 1=6.5 \%$ and $\mathrm{L} 2=22.2 \%)$ and no men were vaccinated $(\mathrm{p}=0.04)$. More women expressed interest in receiving the vaccine than men ( $\circ \mathrm{L} 1=76 \%, \mathrm{~L} 2=65 \%$ and $\delta \mathrm{L} 1=47 \%, \mathrm{~L} 2=40 \%$ ). Comparison among genders regardless of the course showed that the vaccination rate is higher among women $(\mathrm{p}<0.001)$, as is the interest in being vaccinated $(\mathrm{p}=0.004)$. We concluded that the majority of male university students know less about the HPV vaccine than the female ones, use less and are less interested in being vaccinated, in all the groups interviewed. Vaccination coverage is low among the university population and is higher among medical students.

KEYWORDS: HPV. Vaccine. Primary prevention. HPV-related cancer.

\section{INTRODUCTION}

Human papillomavirus (HPV)-related neoplasms include cervical, vulvar, vaginal, penile, anal, rectal and oropharyngeal cancer ${ }^{1}$. More than $80 \%$ of HPVassociated cancers affect the cervix, so most of the scientific evidence of vaccines is related to the cervical disease ${ }^{2}$.

There are currently three prophylactic HPV vaccines. Gardasil®, known as a tetravalent vaccine, which prevents infections from HPV types 6, 11, 16 and 18 and is approved for women aged nine to 45 years and men aged nine to 26 years. Cervarix $^{\circledR}$, also called bivalent vaccine, is effective against HPV types 16 and 18 and is approved for women aged nine and over, with no upper age bracket ${ }^{3,4}$. Gardasil $9^{\circledR}$ vaccine provides coverage for nine HPV types $(6,11,16,18,31,33,45,52,58)$, showing potential coverage of approximately $90 \%$ of vulvar, vaginal, cervical and anal cancers. It is not currently marketed in Brazil ${ }^{3}$.

In March 2014, the Unified Health System (SUS) included the tetravalent HPV vaccine in the National Vaccination Program, targeting girls aged 11-13 years. It is 
currently available for girls aged 9-14 years and boys aged 11-14 years, in two doses with a 6-month interval. It is also available for people living with HIV, transplanted and oncological patients under chemotherapy and radiotherapy, aged 9-26 years, in three doses ${ }^{5}$.

From the beginning of vaccination until June 2017, 18 million doses were applied to the female population nationwide. In the age group of 9-15 years, in the same period, 10.7 million girls received their first dose, which corresponds to $74.7 \%$ of the total Brazilian females in this age group. In total, 7.1 million girls received the full two-dose vaccination schedule recommended by the Ministry of Health, which corresponds to $47 \%$ of the target audience. Regarding boys, from January to June 2017, 853,920 adolescents aged 12-13 years received their first dose of the HPV vaccine, which corresponds to $23.6 \%$ of the 3.61 million boys in this age group ${ }^{5}$. Thus, there is a lower vaccine demand than expected with low vaccination coverage.

The major challenge for public health is to develop accurate forms of communication and information about HPV so that people understand the importance of prevention and problems associated with this virus ${ }^{6}$. To this end, partnerships are being developed with scientific societies and joint work with churches, nongovernmental organizations and the media. The purpose is to clarify that HPV is a public health problem in the country and the importance of vaccination as the most relevant strategy to prevent cervical, vulvar, penile, anal and oropharyngeal cancer.

Accurate knowledge about HPV and its relationship with cervical cancer are critical to make appropriate, evidence-based health care choices. Knowledge levels of students studying at health care-related departments of medical colleges regarding cervical cancer, its risk factors, protection and HPV is important for both, the students and the society in which they will work ${ }^{7,8}$. Literature students will be future teachers. Teachers' knowledge and attitudes towards the vaccine have been shown to significantly affect the success of HPV vaccination programs. Disseminating the correct information about the vaccine is key in ensuring community support ${ }^{9}$.

Due to the low vaccine coverage achieved, this study aimed to evaluate the level of knowledge and use of the HPV vaccine among university students.

\section{METHODS}

This is a cross-sectional study on a population of university students consisting of 301 participants, distributed into groups of 202 medical students from UERJ and UNIFESO (101 freshmen = M1 and 101 from the $6^{\text {th }}$ year $=\mathrm{M} 2$ ) and 99 UERJ literature students ( 50 freshmen $=\mathrm{L} 1$ and 49 of the last year $=\mathrm{L} 2$ ).

A structured questionnaire was distributed to literature and medicine students, and freshmen and last year students were interviewed. This questionnaire evaluated sociodemographic data, life habits, sexual life information and contraception practice, knowledge about the "preventive" exam, knowledge about HPV-induced diseases and HPV vaccine (Figure 1).

The sample size calculation was based on the prevalence of $30 \%$ of HPV infection in sexually active populations ${ }^{10}$. In order to carry out the research, we used the total number of students enrolled in Medicine and Literature courses, which totalize 564 enrollments (282 per year). Assuming an alpha error of 0.05 , the sample size of 206 students (103 students in the first year and 103 in the last year) for the 95\% confidence interval were calculated. A convenience sample was used including all the students (regardless of gender) who agreed to participate.

\section{Ethical aspects}

The research project was conducted in accordance with the standards required by the Declaration of Helsinki and Resolution $\mathrm{N}^{\circ} 466$ of the National Health Council of December 12, 2012. It was by the Research Ethics Committee of HUPE/UERJ in November 25, 2015 (Opinion $\mathrm{N}^{\circ}$ 1.337.349). The questionnaire was randomly applied and all those who agreed to participate signed the Informed Consent Form.

\section{Data review}

The collected variables were used in the comparative analyses to identify prevalence ratios. Data were described by proportions, means, standard deviations, medians and the respective confidence intervals (CI) of 95\% were estimated. The level of associations was evaluated by calculating association measures (odds ratio) and their respective 95\% CIs. Data entry and statistical analysis was carried out with the EPI-INFO 3.5.2 Computational Program.

\section{RESULTS}

\section{Students' profile}

In the group of medical students (M1 and M2), the mean age was $23.7 \pm 4.2$ years and $61.5 \%$ were female. As to ethnicity, $75 \%$ were Caucasian and approximately $95 \%$ were single. Of the group, $11.5 \%$ reported being smokers. Menarche occurred on average at $12.2 \pm 1.3$ years and 


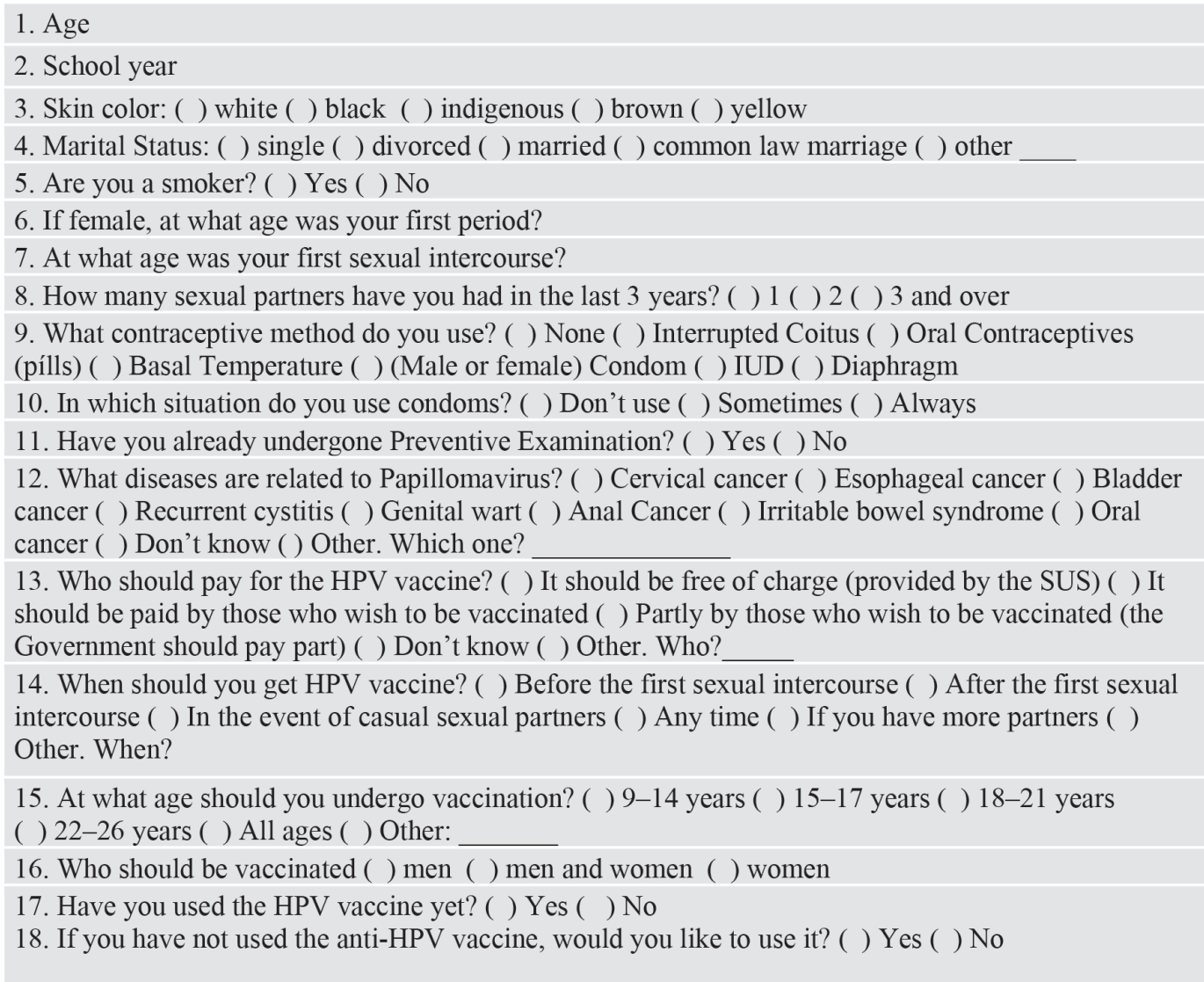

Figure 1 - Questionnaire applied to university students.

sexarch at $17.1 \pm 2.5$ years. The most used contraceptive methods were condoms (53\% in M1 and 27\% in M2) and combined oral contraceptive pills (COCP) $(41.7 \%$ in M1 and $47.9 \%$ in M2). Approximately $4 \%$ of M1 and $16 \%$ of M2 used no method at all. Over $60 \%$ of medical students reported only one sexual partner in the past three years.

In the group of literature students ( 11 and L2), the mean age was $23.2 \pm 6.4$ years and more than $70 \%$ were female. More than half of the students have declared themselves Caucasians and more than $90 \%$ were single. Only $5 \%$ reported smoking. The mean age of menarche was $11.9 \pm 1.7$ years. First sexual intercourse occurred later, with a mean of $18.0 \pm 2.8$ years. Condoms and COCPs were also the most used methods, and in L1 condoms prevailed with $52 \%$, and, in L2, COCPs were predominant, with $44 \%$. Around $85 \%$ of L1 and $64 \%$ of L2 reported using condoms at all times or sometimes, and these were the most significant numbers among the groups studied. Around 54\% of $\mathrm{L} 1$ and $63 \%$ of $\mathrm{L} 2$ reported only one sexual partner in the last three years. (Table 1).

The first sexual intercourse occurred earlier in males $(\mathrm{p}<0.001, \mathrm{OR}=0.37$ [95\% CI 0.22-0.62] $)$ and occurred after the age of 16 in $54 \%$ of medical students and $79 \%$ of literature students.

\section{Vaccine use}

Among medical students, only $21 \%$ of $\mathrm{M} 1$ and $16 \%$ of M2 used the HPV vaccine $(\mathrm{p}=0.35 ; \mathrm{OR}=1.41$ [95\% CI 0.68-2.93]). Comparing by gender, female medical students were vaccinated in greater numbers $(M 1=29.7 \%$ and $\mathrm{M} 2=21.3 \%)$ than male students $(\mathrm{M} 1=5.4 \%$ and $\mathrm{M} 2=7.5 \%)(\mathrm{p}<0.001, \mathrm{OR}=4.92$ [95\% CI 1.92-14.87]). Among literature students, only women received the vaccine ( $\mathrm{L} 1=6.5 \%$ and $\mathrm{L} 2=22.2 \%)$ and none of the males were vaccinated $(\mathrm{p}=0.04, \mathrm{OR}=0.22$ [95\% CI 0.03-1.02]).

\section{Interest in being vaccinated}

Female medical students showed more interest in using the vaccine ( $\mathrm{M} 1=85.1 \%$ and $\mathrm{M} 2=80 \%$ ) than the boys' group ( $\mathrm{M} 1=56.2 \%$ and $\mathrm{M} 2=20.5 \%)$. Likewise, among literature students, more women expressed interest in receiving the vaccine $\left(q \mathrm{~L} 1=76 \%, \mathrm{~L} 2=65 \%\right.$ and ${ }^{\lambda} \mathrm{L} 1=47 \%$, $\mathrm{L} 2=40 \%$ ). However, the difference between courses was not statistically significant $(\mathrm{p}=0.68, \mathrm{OR}=0.85$ [0.37-1.86]) (Figure 2).

Gender comparison regardless of the course showed that the vaccination rate is higher in women $(\mathrm{p}<0.001, \mathrm{OR}=0.19$ 
Table 1 - Analysis of socio-demographic and sexual variables characteristics

\begin{tabular}{|c|c|c|c|c|c|}
\hline & & $1^{\text {st }}$ year Med & Last year Med & $1^{\text {st }}$ year Lit & Last year Lit \\
\hline \multirow{2}{*}{ Age (years) } & $\leq 24$ & $83(82.2 \%)$ & $38(37.3 \%)$ & $41(83.7 \%)$ & $30(61.2 \%)$ \\
\hline & $>24$ & $18(17.8 \%)$ & $64(62.7 \%)$ & $16(3 \%)$ & $19(38.8 \%)$ \\
\hline \multirow{2}{*}{ Sex } & Female & $64(63.3 \%)$ & $61(60 \%)$ & $32(64 \%)$ & $38(84.4 \%)$ \\
\hline & Male & $36(36.6 \%)$ & $40(39 \%)$ & $18(36 \%)$ & $7(15.6 \%)$ \\
\hline \multirow{3}{*}{ Ethnicity } & White & $75(75 \%)$ & $81(7.4 \%)$ & $28(56 \%)$ & $28(57.1 \%)$ \\
\hline & $\begin{array}{l}\text { Mixed ethnicity or } \\
\text { indigenous }\end{array}$ & $16(16 \%)$ & $17(16,6 \%)$ & $12(24 \%)$ & $16(32.7 \%)$ \\
\hline & Black & $9(9 \%)$ & $4(3.9 \%)$ & $10(20 \%)$ & $5(10.2 \%)$ \\
\hline \multirow{2}{*}{ Marital status } & Married/partnership & $5(5 \%)$ & $6(5.8 \%)$ & $1(2 \%)$ & $7(14.3 \%)$ \\
\hline & Not married & $95(95 \%)$ & $96(94.1 \%)$ & $47(95.9 \%)$ & $42(85.7 \%)$ \\
\hline \multirow{2}{*}{ Smoking } & Yes & $9(9 \%)$ & $14(13.8 \%)$ & $2(4.1 \%)$ & $1(2.1 \%)$ \\
\hline & No & $91(91 \%)$ & $88(86.2 \%)$ & $47(95.9 \%)$ & 47 (97.9\%) \\
\hline \multirow{2}{*}{ Menarche (years) } & $<12$ & $17(26.5 \%)$ & $9(25 \%)$ & $15(50 \%)$ & $14(37.8 \%)$ \\
\hline & $\geq 12$ & $47(73.5 \%)$ & $27(75 \%)$ & $15(50 \%)$ & $23(62.2 \%)$ \\
\hline \multirow{2}{*}{ Sexual debut (years) } & $\leq 16$ & $31(43 \%)$ & $43(45.7 \%)$ & $11(3.3 \%)$ & $13(33.3 \%)$ \\
\hline & $>16$ & $41(57 \%)$ & $51(54.3 \%)$ & $23(67.7 \%)$ & $31(79.5 \%)$ \\
\hline \multirow{7}{*}{ Contraceptive method } & vaginal ring & $0(0 \%)$ & $2(2 \%)$ & $0(0 \%)$ & $0(0 \%)$ \\
\hline & hormonal IUD & $0(0 \%)$ & $3(3.2 \%)$ & $0(0 \%)$ & $0(0 \%)$ \\
\hline & Injectable & $1(1.2 \%)$ & $0(0 \%)$ & $0(0 \%)$ & $0(0 \%)$ \\
\hline & $\mathrm{OHC}$ & $30(41.7 \%)$ & $45(47.9 \%)$ & $9(26.5 \%)$ & $18(43.9 \%)$ \\
\hline & withdrawal & 0 & $2(2.1 \%)$ & $1(2.9 \%)$ & $0(0 \%)$ \\
\hline & condom & $38(52.8 \%)$ & $26(27.6 \%)$ & $18(52.9 \%)$ & $15(36.7 \%)$ \\
\hline & no methodi & $3(4.1 \%)$ & $15(16 \%)$ & $6(17.6 \%)$ & $8(19.5 \%)$ \\
\hline \multirow{3}{*}{ Condom use } & always & $42(60 \%)$ & $30(32 \%)$ & $23(67.6 \%)$ & $19(48.7 \%)$ \\
\hline & sometimes & $18(26 \%)$ & $38(40 \%)$ & $6(17.6 \%)$ & $6(15.8 \%)$ \\
\hline & never & $9(13 \%)$ & $26(27.6 \%)$ & $5(14.7 \%)$ & $14(35.9 \%)$ \\
\hline \multirow{3}{*}{ Partners in the last 3 years } & $0-1$ & $33(61 \%)$ & $36(64.2 \%)$ & $13(54.2 \%)$ & $17(63 \%)$ \\
\hline & 2 & $13(24 \%)$ & $10(17.8 \%)$ & $11(45.8 \%)$ & $10(37 \%)$ \\
\hline & $3-5$ & $8(14.8 \%)$ & $10(17.8 \%)$ & $0(0 \%)$ & $0(0 \%)$ \\
\hline
\end{tabular}

Med= Medicine; Lit= Literature; IUD= intrauterine device; $\mathrm{OHC}=$ oral hormonal contraceptive

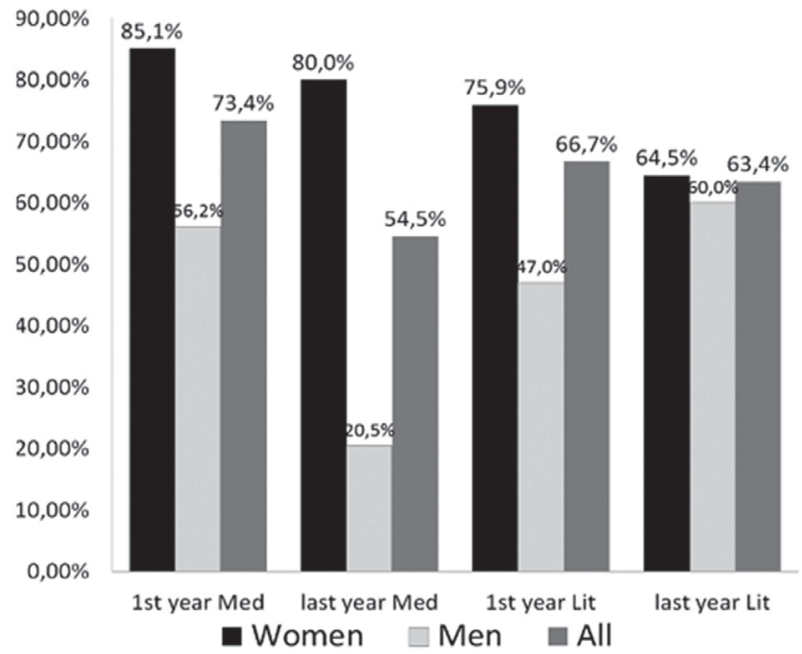

Figure 2 - Interest in being vaccinated according to gender. Med= Medicine; Lit= Literature.
[95\% CI 0.06-0.47]), as is the interest in vaccination $(\mathrm{p}=0.004, \mathrm{OR}=0.45[95 \%$ CI $0.25-0.79])$.

\section{Who must be vaccinated}

In M1, 44\% believe that only women should be vaccinated and $56 \%$ agree that both genders should have access. In M2, opinions are reversed. Among medical students, most believe that it should be administered only before the first sexual intercourse and most know that the age for vaccination by the SUS is between the ages of 9 and 14. Literature students diverged on who should use the vaccine, since although $61 \%$ of L1 and $47 \%$ of L2 agree that it should be provided for both genders, $38 \%$ of L1 think it is only for women and $34 \%$ of L2 think that only men should use it. While slightly more than $50 \%$ of both groups agree 
Table 2 - Level of knowledge about HPV vaccine among medical and literature students

\begin{tabular}{|c|c|c|c|c|c|}
\hline & & $1^{\text {st }}$ year Med & Last year Med & $1^{\text {st }}$ year Lit & Last year Lit \\
\hline \multirow{3}{*}{$\begin{array}{l}\text { Who should pay for } \\
\text { vaccination? }\end{array}$} & Unified Health System & $62(61,3 \%)$ & $81(80 \%)$ & $44(88 \%)$ & $44(89,8 \%)$ \\
\hline & Others & $27(26,7 \%)$ & $16(15,8 \%)$ & $1(2 \%)$ & $2(4 \%)$ \\
\hline & Don't know & $12(11,8 \%)$ & $4(4 \%)$ & $5(10 \%)$ & $3(6,2 \%)$ \\
\hline \multirow{3}{*}{ Who should get vaccinated? } & Women & $44(44 \%)$ & $57(56,4 \%)$ & $18(38,3 \%)$ & $9(19,2 \%)$ \\
\hline & Men and women & $56(56 \%)$ & $43(42,5 \%)$ & $29(61,7 \%)$ & $22(46,8 \%)$ \\
\hline & Men & $0(0 \%)$ & $1(0 \%)$ & $0(0 \%)$ & $16(34 \%)$ \\
\hline \multirow{5}{*}{$\begin{array}{l}\text { When vaccine should be } \\
\text { given? }\end{array}$} & Before the sexarch & $83(83 \%)$ & $76(74,5 \%)$ & $24(51,1 \%)$ & $26(54,2 \%)$ \\
\hline & After the sexarche & $0(0 \%)$ & $4(3,9 \%)$ & $3(6,4 \%)$ & $3(6,3 \%)$ \\
\hline & Casual relashionship & $1(1 \%)$ & $0(0 \%)$ & $4(8,5 \%)$ & $3(6,3 \%)$ \\
\hline & If more than one partner & $0(0 \%)$ & $0(0 \%)$ & $1(2,1 \%)$ & $0(0 \%)$ \\
\hline & Any time & $5(5 \%)$ & $11(10,8 \%)$ & $15(31,9 \%)$ & $16(33,4 \%)$ \\
\hline \multirow{5}{*}{ Age for vaccination by SUS } & $>9$ & $10(10 \%)$ & /6 (5,9\%) & $2(4,5 \%)$ & $5(10,6 \%)$ \\
\hline & 9 a 14 & $76(76 \%)$ & $76(74,5 \%)$ & $23(52,3 \%)$ & $24(51 \%)$ \\
\hline & 15 a 17 & $13(13 \%)$ & $11(10,8 \%)$ & $11(25 \%)$ & $13(27,7 \&)$ \\
\hline & 18 a 21 & $0(0 \%)$ & $1(0 \%)$ & $6(13,6 \%)$ & $3(6,4 \%)$ \\
\hline & 22 a 26 & $1(1 \%)$ & $0(0 \%)$ & $2(4,5 \%)$ & $1(2,1)$ \\
\hline
\end{tabular}

Med=Medicine; Lit=Literature; SUS - Sistema Unico de Saude (Unified Health System)

that the vaccine should be given before the sexarch, $32 \%$ believe it can be used at any time. Most literature students know that the age for vaccination by the SUS is between 9 and 14 years old (Table 2).

\section{DISCUSSION}

HPV infection has alarming proportions and is a predisposing factor for several types of cancers, including cervical, vaginal, anal and oropharyngeal cancer. From these data, it is possible to characterize HPV as a public health problem. The infection predominantly affects young, sexually active adults of both genders ${ }^{11}$.

In Brazil, data from the National Adolescent Schoolbased Health Survey (PeNSE) in 2009, in the Brazilian capitals, showed that, among adolescents aged 14 who have already had sexual intercourse, more than a third had their first sexual intercourse at 12 years old or less. Studies show that early sexual intercourse is associated with unprotected sex and more partners over a lifetime ${ }^{12}$.

This study was carried out with students of the first and last year of Medicine and Literature courses and the main results showed that most students did not know that vaccination could also be done after sexarch, and female students showed more interest in using the vaccine than male students in both groups (literature and medical students).

The mean age of the students was 23 years in both courses. As expected, most were single and young, up to 24 years of age. The first sexual intercourse occurred on average at the age of 17 among medical students and 18 among literature students, and was earlier in males $(\mathrm{p}<0.001)$. These results are in agreement with two large Brazilian studies, the ERICA study with 74,589 Brazilian adolescents who showed the first sexual intercourse in $28.1 \%$ of adolescents, with a higher prevalence around 17 years old $(56.4 \%)$ and in males $(33.5 \%)$, and the National School Health Survey (PeNSE) conducted in 2012, which showed sexual activity in $28.7 \%$ (95\% CI 26.4-31.2) of ninth grade students, usually aged 14 to 15 years, including $18.3 \%$ (95\% CI: $15.3-21.8)$ of girls and $40.1 \%$ (95\% CI 26.4-31.2) of boys ${ }^{12,13}$.

Regarding the use of contraceptive methods, freshmen of both courses reported condom use in $53 \%$, with lower use among the last-year students $(27.6 \%$ and $36.7 \%$, respectively). Almost half of seniors use combined oral contraceptive pills (COCP). Based on this finding, it can be assumed that because graduating students are older, they are probably in a stable relationship. It is interesting to note that greater knowledge about sexually transmitted infections (STIs) and prevention of these diseases does not imply a greater use of the method, since the COCP is the most used method by M2, while condom is the most used method by M1.

For those who received the vaccine, the study showed that women were vaccinated in larger numbers than men, and that, among literature students, no males used 
the vaccine. These results are similar to those of Yam et $a l .{ }^{14}$ in Hong Kong, who found adherence to the vaccine of $45.2 \%$ of women and $8.8 \%$ of men. This can be attributed to the fact that the vaccine development and implementation strategy has been specifically focused on women with the aim of preventing cervical cancer, resulting in vaccine feminization ${ }^{15}$. In addition, women are the focus of procreative responsibility, thus bearing the burden of contraceptive liability. According to official data, the contraceptive pill is used by $27.4 \%$ of Brazilians, with sterilization appearing as the second contraceptive method, adopted by $25.9 \%$. Vasectomy is less frequently reported, by only $5 \%$ of males ${ }^{16}$.

Low vaccine adherence in this study (less than $1 / 3$ of all respondents) can also be explained by the fear of the ensuing risks of vaccination. This was also reported by Yam et $a l .{ }^{14}$ who found that $33.1 \%$ of university respondents were concerned about the side effects of the HPV vaccine. A study conducted in Canada analyzing online comments on news sites to understand public perceptions of $\mathrm{HPV}^{17}$ identified several negative comments regarding the composition of the vaccine, the unknown effects and as a cause of chronic diseases, showing a lack of knowledge of the population on the benefits of the vaccine.

Another hypothesis for the low number of vaccinees may be associated with the stigmatic and promiscuous view regarding the use of a vaccine that protects against STIs. Wong and Sam showed that $11.3 \%$ of women who did not receive the HPV vaccine reported shame of being vaccinated against STIs ${ }^{18}$.

Regarding the interest in being vaccinated, this study observed that more female students showed interest in using the vaccine in all groups. In general, students who are starting higher education are more interested in being vaccinated. This may be due to the relatively recent implementation of the HPV vaccine in Brazil, so that students still in the undergraduate years experienced more effectively vaccination campaigns and were aware of the importance of vaccination. In addition, as the focus of the campaign was the female audience, from the moment the government provided the vaccine for free in 2014, it was directed exclusively to women, and it was expected that the public would become more aware of and interested in vaccination ${ }^{19}$. The low interest of the male public may be partially attributed to the focus mostly given to cervical cancer in the HPV vaccine campaign, so that information such as the prevention of penile, anal, and oropharyngeal cancer had not been highlighted ${ }^{14}$.

In respect to those who should be vaccinated among Medicine and Literature freshmen, the view that both genders should have access to the vaccine prevailed, in last-year students of both courses most students believed that only women should be vaccinated. Once again, consideration should be given to the recent implementation of the HPV vaccine in Brazil and its vaccine campaign focused on women ${ }^{19}$. These data are in line with research conducted with students at a university in India ${ }^{20}$, which has shown that more than half of the students agree that only women should be vaccinated. This fact is worrisome, because men play a significant role in the transmission of the disease, since most of them have more sexual partners than women and, due to their low adherence to the tests, they end up not knowing that they have the disease.

Yam et al. ${ }^{14}$ observed that medical students, especially those most advanced in the course, had broader knowledge and positive attitudes about HPV vaccination, a behavior attributed to information received during university years, while students from other courses had less access to medical knowledge, and it was reasonable for these students to be less informed about HPV infection and its vaccine. However, when analyzing the vaccination practice in these two groups, there was no significant difference. On the other hand, our data showed that undergraduate students of the two courses have more knowledge about the vaccine than their veterans, while sixth-year medical students have shown a greater technical knowledge about HPV infection, associated pathologies and other aspects. Nonetheless, when analyzing the vaccination rate in these two groups, there was also no significant difference. The higher level of knowledge of students and health professionals about the HPV vaccine can contribute to an increased vaccination coverage, since they begin to have a positive perception, starting to recommend it to their patients. In an open letter to physicians, the Brazilian Society of Immunizations (SBIm), the Brazilian Society of Infectology (SBI), the Brazilian Society of Pediatrics (SBP) and the Brazilian Federation of Gynecology and Obstetrics Associations (FEBRASGO) have warned on how prescription of the HPV vaccine may change the current reality of low vaccine coverage. "Recent studies show that patients receiving recommendation from their doctors are four to five times more likely to get vaccinated. A hesitant, vague or sturdy recommendation may lead the patient to believe that the HPV vaccine is not as important as the others" ${ }^{21}$. This rationale is confirmed by a study that showed that students with higher levels of knowledge were more motivated to use and recommend vaccination ${ }^{22}$. A study conducted with medical students and physicians at the Federal University of Parana showed that more than half of the respondents would indicate the vaccine to boys and girls between the ages of 10 and $15^{23}$.

As for the vaccination timing, more than $80 \%$ of medical students and more than $50 \%$ of literature students believe 
that the HPV vaccine should be given only before the sexarch. When implemented in the National Vaccination Program, the HPV vaccine targeted girls aged 11-13 years, an age range that was increased, and now covers girls aged 9-14 years and boys aged $11-14$ years ${ }^{19}$. This change aims to reach the public before the onset of the sexual life and, consequently, before the contact with the virus. However, the vaccine can be purchased in private clinics for the remaining individuals and is important to protect against HPV types that have not yet been acquired.

It is also possible to understand the importance of vaccination in women diagnosed with HPV to prevent new infections, since the subgroup undergoing prior vaccination evidenced a significant reduction in the incidence of subsequent HPV-related diseases, including severe lesions ${ }^{24}$.

One of the limitations of this study is that it is a cross-sectional study and the participants represented a convenience sample. After a pilot-testing questionnaire with ten students, we have changed some questions in order to facilitate reading and answering. It was found that dealing with questions directed to sexuality still generates certain discomfort and insecurity, especially for adolescents and young adults. Some participants have questioned, even after signing the Informed Consent Form, about the secrecy of the data and refused to respond after reading the content of the questionnaire. As the research included only students of medicine and literature, we cannot generalize the knowledge regarding HPV-induced diseases and the benefits of vaccination to the general public and to the universe of university students.

Thus, it is evident that, following what is expected in a wider context of dichotomization of vaccine use at a university level, male students are less knowledgeable about HPV vaccination than women, use less the vaccine and show less interest in being vaccinated in all groups interviewed. In addition, vaccination coverage is low among the university population and is higher among medical students. As already mentioned, it may be a result of the recent free implementation of the HPV vaccine in Brazil that did not include a large part of the public interviewed due to the age group, as well as the cost of the vaccine in private clinics. This reflects the difficulty of dealing with HPV as a collective health problem, and it is necessary to rethink its approach in order to achieve more solid and safe immunization rates for the population as a whole.

\section{AUTHORS' CONTRIBUTIONS}

Conceived and designed the experiments: DLMM, LCSB, MAPO, AJBT. Performed the experiments:
DLMM, TPS, JRPS, GRS, TC, JTC. Analyzed the data: DLMM, LCSB, MAPO. Contributed to the writing of the manuscript: DLMM, LCSB, TPS, JRPS, GRS, TV, JTC E AJBT. Review: DLMM e LCSB.

\section{REFERENCES}

1. Centers for Disease Control and Prevention. How many cancers are linked with HPV each year? [cited 2017 Oct 11]. Available from: https://www.cdc.gov/cancer/hpv/statistics/cases.htm

2. Bray F, Ferlay J, Laversanne M, Brewster DH, Gombe Mbalawa C, Kohler B, et al. Cancer incidence in five continents: inclusion criteria highlights from volume $\mathrm{X}$ and the global status of cancer registration. Int J Cancer. 2015;137:2060-71.

3. World Health Organization. Human papillomavirus vaccines: WHO position paper, October 2014. Wkly Epidemiol Rec. 2014;43:465-92.

4. Cervarix human papillomavirus vaccine [types 16, 18] (recombinant, adjuvanted, adsorbed) [package insert]. London: European Medicines Agency; 2016. [cited 2018 Jul 25]. Available from: http://www.ema.europa.eu/docs/ en_GB/document_library/EPAR_-_Summary_for_the_public/ human/000721/WC500024634.pdf

5. Brasil. Ministério da Saúde. Saúde amplia vacinação de HPV para homens e mulheres até 26 anos. Brasília; Ministério da Saúde; 2017. [cited 2018 Jul 25]. Avaliable from: http://portalms. saude.gov.br/noticias/svs/29281-saude-amplia-vacinacao-dehpv-para-homens-e-mulheres-ate-26-anos

6. Pitts M, Clarke T. Human papillomavirus infections and risks of cervical cancer: what do women know? Health Educ Res. 2002;17:706-14.

7. Yörük S, Açıköz A, Ergör G. Determination of knowledge levels, attitude and behaviors of female university students concerning cervical cancer, human papiloma virus and its vaccine. BMC Womens Health. 2016;16:51.

8. Tiro JA, Meissner HI, Kobrin S, Chollette V. What do women in the U.S. know about human papillomavirus and cervical cancer? Cancer Epidemiol Biomarkers Prev. 2007;16:288-94.

9. Masika MM, Ogembo JG, Chabeda SV, Wamai RG, Mugo N. Knowledge on HPV vaccine and cervical cancer facilitates vaccine acceptability among school teachers in Kitui County, Kenya. PLoS One. 2015;10:e0135563.

10. Monteiro DL, Trajano AJ, Silva KS, Russomano FB. Incidence of cervical intraepithelial lesions in a population of adolescents treated in public health services in Rio de Janeiro, Brazil. Cad Saude Publica. 2009;25:1113-22.

11. Palefsky JM, Hirsch MS, Bloom A. Human papillomavirus infections: epidemiology and disease associations. Waltham: UpToDate; 2018. [cited 2018 Jul 25]. Available from: https://www.uptodate.com/contents/human-papillomavirusinfections-epidemiology-and-disease-associations 
12. Oliveira-Campos M, Nunes ML, Madeira FC, Santos MG, Bregmann SR, Malta DC, et al. Sexual behavior among Brazilian adolescents, National adolescent school-based Health Survey (PeNSE 2012). Rev Bras Epidemiol. 2012;17 Suppl 1:116-30

13. Borges AL, Fujimori E, Kuschnir MC, Chofakian CB, Moraes AJ, Azevedo GD, et al. ERICA: sexual initiation and contraception in Brazilian adolescents. Rev Saude Publica. 2016;50 Suppl $1: 15 \mathrm{~s}$.

14. Yam PW, Lam PL, Chan TK, Chau KW, Hsu ML, Lim YM, et al. A cross sectional study on knowledge, attitude and practice related to Human Papillomavirus vaccination for cervical cancer prevention between medical and non-medical students in Hong Kong, Asian Pac J Cancer Prev. 2017;18:1689-95.

15. Daley EM, Vamos CA, Thompson EL, Zimet GD, Rosberger Z, Merrell L, et al. The feminization of HPV: how science, politics, economics and gender norms shaped U.S. HPV vaccine implementation. Papillomavirus Res. 2017;3:142-8.

16. Perpétuo IG, Wong LL. Desigualdade socioeconômica na utilização de métodos anticoncepcionais no Brasil: uma análise comparativa com base nas PNDS 1996 e 2006. In: Brasil. Ministério da Saúde. Centro Brasileiro de Análise e Planejamento. Pesquisa Nacional de Demografia e Saúde da Criança e da Mulher: PNDS 2006: dimensões do processo reprodutivo e da saúde da criança. Brasília: Ministério da Saúde; 2009. p.87-104. [cited 2018 Jul 25]. Avaliable from: http://bvsms.saude.gov.br/bvs/publicacoes/pnds_crianca_ mulher.pdf

17. Feinberg Y, Pereira JA, Quach S, Kwong JC, Crowcroft NS, Wilson SE, et al. Understanding public perceptions of the HPV vaccination based on online comments to canadian news articles. PLoS One. 2015;10:e0129587.
18. Wong LP, Sam IC. Ethnically diverse female university students' knowledge and atitudes toward human papillomavirus (HPV), HPV vaccination and cervical cancer. Eur J Obstet Gynecol Reprod Biol. 2010;148:90-5.

19. Brasil. Ministério da Saúde. Secretaria de Vigilância em Saúde. Departamento de Vigilância das Doenças Transmissíveis. Coordenação Geral do Programa Nacional de Imunizações. PNI - Programa Nacional de Imunizações: boletim informativo do PNI-02/2016: vacinação contra HPV. Brasília: Ministério da Saúde; 2016. [cited 2018 Jul 25]. Avaliable from: http:// www.conasems.org.br/wp-content/uploads/2016/10/images_ Boletim_informativo_HPV002-2016.pdf

20. Rashid S, Labani S, Das BC. Knowledge, awareness and attitude on HPV, HPV vaccine and cervical cancer among the college students in India. PLoS One. 2016;11:e0166713.

21. Sociedade Brasileira de Imunizações, Sociedade Brasileira de Infectologia, Sociedade Brasileira de Pediatria, Federação Brasileira das Associações de Ginecologia e Obstetrícia. Vacina HPV: carta aberta aos médicos. [cited 2018 Jan 22]. Available from: https://sbim.org.br/notas-e-informes-tecnicos/49-vacinahpv-carta-aberta-aos-medicos

22. Chen JM, Leung DY. Factors associated with human papillomavirus vaccination among Chinese female university students in Hong Kong. Am Int J Soc Sci. 2016;3:56-62.

23. Carvalho NS, Teixeira LM, Pradel EM, Gabardo J, Joly C, Urbanetz AA. Vaccinating against HPV: physicians' and medical students' point of view. Vaccine. 2009;27:2637-40.

24. Joura EA, Garland SM, Paavonen J, Ferris DG, Perez G, Ault KA, et al. Effect of the human papillomavirus (HPV) quadrivalent vaccine in a subgroup of women with cervical and vulvar disease: restrospective pooled analysis of trial data. BMJ. 2012;344:e1401. 